\title{
Doença mental e periculosidade criminal na psiquiatria contemporânea: estratégias discursivas e modelos etiológicos
}

I ${ }^{1}$ Myriam Raquel Mitjavila, ${ }^{2}$ Priscilla Gomes Mathes I

Resumo: O artigo analisa algumas dimensões socioculturais do campo semântico e dos modos de estruturação dos discursos da psiquiatria forense em torno da periculosidade criminal e de suas conexões com a saúde mental. A partir dos resultados de uma pesquisa baseada na análise de conteúdo de uma amostra de manuais e livros de psiquiatria forense, examinaram-se alguns significados e formas de enunciação da noção de periculosidade criminal, bem como as principais estratégias interpretativas que organizam os modelos etiológicos da criminalidade predominantes nessa área.

> Palavras-chave: Periculosidade criminal; psiquiatria forense; doença mental.

\author{
1 Doutorado e Pós-Doutorado \\ em Sociologia (USP). Professora \\ Adjunta IV do Departamento de \\ Serviço Social e do Programa de \\ Pós-Graduação Interdisciplinar \\ em Ciências Humanas da \\ Universidade Federal de Santa \\ Catarina. Endereço eletrônico: \\ myriammitjavila@gmail.com \\ ${ }^{2}$ Doutoranda do Programa de \\ Pós-Graduação Interdisciplinar \\ em Ciências Humanas. Endereço \\ eletrônico: priscilla_mathes@ \\ yahoo.com.br
}

Recebido em: 29/02/2012. Aprovado: 20/09/2012. 
O artigo tem o propósito de indagar algumas dimensóes do campo semântico e dos modos de estruturação dos discursos contemporâneos da medicina psiquiátrica em torno da periculosidade criminal e de suas conexões com a saúde mental. A análise dessa problemática se apoia nos resultados de uma pesquisa na qual foram examinadas treze obras consideradas materiais de referência técnica na área da psiquiatria forense $e^{1}$.

Atualmente, não existe consenso na literatura médica sobre as relações entre doença mental e criminalidade, do ponto de vista do valor etiológico da primeira para predizer a segunda. No entanto, isso não parece ter sido um impedimento para que o campo jurídico-penal tenha continuado a instituir para a medicina psiquiátrica o caráter de único saber com competência técnica e amparo legal para determinar a periculosidade criminal de indivíduos diagnosticados como doentes ou portadores de transtornos mentais.

Ao longo do artigo, discute-se se existiria uma contradição entre as expectativas do poder judiciário e os questionamentos e relativizações que abundam na literatura médico-psiquiátrica sobre as relações entre doença mental e periculosidade criminal. Propõe-se o caráter mais aparente que real dessa contradição, em virtude de a doença mental não ter sido, historicamente, o único nem o principal fundamento da participação da psiquiatria na abordagem da periculosidade criminal. Por outro lado, mais recentemente, esse fato pode ser observado a partir da notória substituição da noção de doença ou patologia pelo conceito de "transtorno" como fator etiológico da periculosidade criminal. Não será mais a loucura - como acontecia nos primórdios da psiquiatria -, e sim uma classe particular de transtorno, o "transtorno de personalidade antissocial" (TPAS), o que se converterá em peça-chave da ampliação do universo de objetos compreendidos nos processos contemporâneos de medicalização do crime.

\section{Sedimentos históricos da noção de periculosidade criminal na psiquiatria}

Enquanto fenômeno social, a atividade forense da psiquiatria moderna encontrase localizada em espaços nevrálgicos das relações entre indivíduos e instituições sociais. Com efeito, a esfera da justiça tem desempenhado um papel bastante relevante quanto à construção e regulação dessas relaçôes, através de processos 
que atingem praticamente todas as áreas de funcionamento da vida social (infância, juventude, família, atividade econômico-financeira, crime, etc.). Interessa, portanto, situar a atividade forense da psiquiatria no interior de uma problemática mais ampla, que remeta aos processos por meio dos quais as instituições modernas se apoiam em agentes, saberes e mecanismos para avaliar ou julgar indivíduos ou situações de acordo com imperativos e normas estratégicas para a construção da ordem social (MITJAVILA, 1998; ELIAS, 1994; DOUGLAS, 1990; FOUCAULT, 1977; 1987).

A configuração da Psiquiatria como campo de saber e exercício de poder teria suas origens, de acordo com Foucault (2006), nos primeiros anos do século XIX, sob a forma de uma "protopsiquiatria", a qual carecia ainda de uma natureza propriamente terapêutica, mas já era uma forma particular de administrar e de gerir a loucura. Nessa época, o psiquiatra é caracterizado como "alguém que dirige o funcionamento do hospital e os indivíduos” (2006, p.218).

Quanto à psiquiatria forense, o que se percebe é que a relação entre a doença mental e as leis não seguiu a mesma evolução dos conhecimentos sobre a doença mental em si. De fato, observa-se que tanto médicos como legisladores não estavam preocupados com as causas e as classificações da doença psíquica, mas sim com as providências legais a serem tomadas de acordo com a integridade mental do indivíduo. Especificamente no contexto europeu, na segunda metade do século XIX, aparecem as primeiras instituições para tratamento de doentes mentais perigosos. (RIGONATTI, 2003). Com a criação da Psiquiatria como especialidade médica, a relação entre Justiça e Saúde Mental começou a ser abarcada por uma profissão, passando a existir, assim, a psiquiatria forense como subespecialidade da própria psiquiatria, responsável por utilizar os conhecimentos científicos psiquiátricos a serviço da justiça. (RIGONATTI, 2003).

A obra de Morel (1809-1873) e sua noção de degenerescência foram decisivas no desenvolvimento e na trajetória da psiquiatria forense (FOUCAULT, 2006). A degenerescência como predisposição que apresentava traços morais e - principalmente - físicos se tornará peça-chave das relações entre loucura e criminalidade. Dessa forma, a noção de degeneração cumpriu um papel geneticamente relevante no estabelecimento das relaçóes entre loucura e criminalidade. A ideia de degeneração baseia-se nos conceitos de norma e normalidade, pois, conforme apontado por alguns autores, 
[...] refere-se a um duplo desvio: por um lado, desvio da frequência estatística desejada em relação a características físicas, tais como altura, peso, formato do rosto, das orelhas, etc. - os chamados estigmatas (CARTRON, 2000); por outro, desvio das normas ou valores que a sociedade europeia do século XIX considerava como invioláveis e universais (CAPONI, 2009, p.537, grifo do autor)

Essa percepção dará início a "estudos que se inscrevem na chamada teoria da degeneração", que serão capazes de centralizar os esforços dos psiquiatras, médicos, juristas e higienistas para tentar "definir a abrangência e os limites do conceito de degeneração" (p. 537). Para Foucault (2002), a noção de degeneração será elemento teórico chave da medicalização do anormal. Na perspectiva foucaultiana, o degenerado passa a ser o anormal medicalizado.

Por volta de 1876, a relação entre loucura e crime ganha destaque com a figura de Cesare Lombroso (1836-1909), considerado o criador da antropologia criminal (RIGONATTI, 2003) e o pai da criminologia (MORAES; FRIDMAN, 2004). Ele apresenta o conceito de "criminoso nato" e estabelece as bases da interpretação etiológica do crime em função de parámetros biológicos, a partir da teoria da degeneração de Morel. Em 1885, no Primeiro Congresso Internacional de Antropologia Criminal, Lombroso afirmou que o criminoso nato estava "predisposto ao crime por sua constituição física", e que apoiava esse enunciado na "observação positiva dos fatos" (DARMON, 1991, p.37). O foco de sua atenção era o criminoso mais do que o crime em si. "Para Lombroso, os germes da loucura moral e do crime se encontrariam não por exceção, mas de maneira natural nos primeiros anos da vida do homem.” (p.45).

Na perspectiva lombrosiana, o crime é um fenômeno natural do ser humano e, da mesma forma que a natureza, precisa ser estudado com atenção para atender a uma finalidade muito precisa: preveni-lo. Nesse contexto, e em função do caráter hereditário que atribuía à criminalidade, Lombroso cria a noção de "criminoso nato", tributária da teoria da degenerescência formulada por Morel em 1857. (JACÓ-VILELA et al., 2005).

Dentre os "criminosos natos", os "loucos morais" são os que despertam maior interesse entre alienistas de diferentes países, na passagem do século XIX para o $\mathrm{XX}$, e continuam a fazê-lo ainda hoje, porém sob formas renovadas. Caracterizados pela dificuldade de distinguir o bem do mal (ou para orientar suas vidas em função do que em determinado contexto se considera moralmente correto), esses "loucos morais", seriam uma subcategoria perigosa de criminoso (DARMON, 1991). 
Trata-se de uma percepção da loucura em sua peculiar associação com uma incapacidade ou ausência de autocontrole dos impulsos. Esse aspecto se torna etiologicamente importante na avaliação psiquiátrica da criminalidade, no sentido de ser um pré-anúncio de atos criminosos futuros, decorrentes do "acting out" do doente mental. Esse tipo de avaliação psiquiátrica se constitui, basicamente, de qualificações morais, fazendo com que se torne possível construir um novo tipo de discurso que será uma versão psicológica e ética do delito. Ao fazer isso, a psiquiatria deslegaliza a infração tal como ela é determinada na legislação e faz do delito uma irregularidade frente a regras morais, sociais, psicológicas e também fisiológicas. Com isso, o que o juiz vai condenar não é mais o delito, o crime, e sim as condutas irregulares do indivíduo que os originaram (FOUCAULT, 2002).

Nesse novo quadro de produção de verdade sobre a loucura e a criminalidade, a "biografização" tornou-se uma estratégia argumentativa relevante. Se, inicialmente, o psiquiatra era chamado para periciar sobre o estado de demência do autor de um crime no momento do ato, definindo se ele era ou não responsável pelos seus atos no instante do delito, a partir do século XVIII, o exame passa a focalizar os antecedentes do crime no próprio criminoso. $\mathrm{O}$ objetivo seria pôr em evidência o que Foucault (2002) chama de condições parapatológicas, fazendo com que apareça como doença o que não é uma doença, por meio da patologização de um defeito moral. Como se verá mais adiante, a biografização, enquanto estratégia da anamnese que comanda o interrogatório forense, permanece nos tempos atuais como um dos principais recursos da psiquiatria na arbitragem da criminalidade.

A biografização não proporciona, em si mesma, explicações do ato criminoso, mas estabelece analogias entre o crime e determinadas situações da vida do periciado. Essa característica do exame médico-legal funciona contemporaneamente como uma ponte entre categorias jurídicas, de forma que a não punição de um indivíduo devido a sua imaturidade psicológica ou personalidade pouco estruturada possa estar incluída no discurso médico psicopatológico, substituindo a prisão por uma instituição alternativa: o hospital psiquiátrico. O encerro e sua duração já não desvelam tanto, uma vez que as chances de sair do hospital psiquiátrico, efetivamente, são menores do que no caso da prisão, devido à ausência de prazos preestabelecidos e ao fato de sua cessação ou perpetuação dependerem unicamente da avaliação psiquiátrica (FOUCAULT, 2002). 
A lógica do julgamento e da administração de penas nessa área se apoia na noção de periculosidade. $\mathrm{O}$ indivíduo localizado exatamente no limiar da loucura e da criminalidade é o indivíduo perigoso, que não pode permanecer na sociedade. É necessário, portanto, institucionalizá-lo, seja no espaço da prisão, no polo judiciário, ou em hospital psiquiátrico, no terapêutico. Com isso, apresentase o problema "[...] do perigo social: isto é, ele será também o discurso do medo, um discurso que terá por função detectar o perigo e opor-se a ele. É, pois, um discurso do medo e um discurso da moralização [...]" (FOUCAULT, 2002, p.44).

A mesma psiquiatria que ampliou dessa forma os limites da anormalidade-e que desempenhou funções de controle social embasadas na teoria da degenerescência de Morel e na antropologia criminal lombrosiana - desembarcou na sociedade brasileira, onde encontrou um terreno propício para se desenvolver. Sua orientação moralizadora já podia ser observada nas diretrizes da Liga Brasileira de Higiene Mental (LBHM), criada em 1923, no Rio de Janeiro. Seus psiquiatras faziam parte, também, da elite do Rio de Janeiro e da psiquiatria brasileira, e se engajaram em campanhas públicas nas quais se definiam como higienistas. Segundo Costa (1976), a atmosfera psiquiátrica do Brasil estava repleta de conotações ideológicas, e a psiquiatria contribuiu significativamente a nutrir o contingente de empresários morais das diversas campanhas que preconizaram normas e valores em defesa da higiene e da saúde pública. Nesse contexto, o caráter eugênico das intervenções médicas não pode ser negligenciado, já que representou uma estratégia que permitiu ampliar as fronteiras da medicalização da vida social, justificando, assim, os anseios culturais dos psiquiatras e seus caminhos ideológicos. Destacamse os trabalhos de Raimundo Nina Rodrigues, que abordam as relações entre raça e crime, atribuindo à mestiçagem o papel de fator decisivo de degeneração (DELGADO, 1992), e de Heitor Carrilho, que se apoiou na noção de "estado degenerativo" como fundamento diagnóstico, no qual o crime seria apenas um sintoma da anormalidade do indivíduo criminoso e, não poucas vezes, seria o único sintoma perceptível (JACÓ-VILELA et al., 2005).

Portanto, a principal característica dos objetos da psiquiatria forense na área criminal seria sua natureza moral e social. Devido a isso, já nos códigos penais do seculo XIX, esse caráter da intervenção psiquiátrica se manifestava toda vez que se tratava de avaliar o "estado psicológico do réu antes e durante o crime", como insumo de grande valor para os magistrados investigadores (HARRIS, 
1993, p.142). No entanto, o estatuto conceitual e o significado político da

questão da periculosidade criminal são, ainda hoje, focos de problematização no interior da própria psiquiatria.

\section{Doença mental e periculosidade criminal}

Tanto na literatura internacional como nos materiais bibliográficos examinados no âmbito do presente artigo, abundam questionamentos e relativizaçôes sobre a periculosidade como um atributo dos doentes mentais. Recentemente, um psiquiatra brasileiro manifestava com veemência seu rechaço a considerar qualquer tipo de ingerência da psiquiatria nas avaliações de periculosidade criminal:

$\mathrm{O}$ tema da periculosidade jamais foi discutido seriamente pelos psiquiatras. Periculosidade é uma questão social e jurídica, porém absolutamente fora do campo psicopatológico. O que o psiquiatra pode dizer sobre o examinando restringe-se à sua saúde mental. Existem pessoas perigosíssimas sem nenhum problema psiquiátrico, e vice-versa. $^{2}$ (BASTOS, 2007)

Ou, ainda, na concepção de Taborda (2004), “[...] cabe formular a questão: o doente mental será de fato o melhor exemplo de indivíduo perigoso na realidade brasileira?". O autor ensaia uma resposta na qual ressalta a função da psiquiatria de mostrar para a sociedade que o crime em realidade seria o resultado de "[...] fatores culturais prevalentes em uma sociedade enferma em termos de conduta moral" (TABORDA, 2004, p.23).

Ao mesmo tempo, a posição majoritariamente encontrada na literatura da área caracteriza-se por questionar o grau e alcance das relaçôes entre doença mental e periculosidade criminal, sobretudo a partir de resultados de pesquisas de origem anglo-saxônica que destacam a existência de fracas ou nulas correlações entre ambas as variáveis, principalmente nos casos de estudos populacionais (VALENÇA; MORAES, 2006).

Embora muitos autores questionem a suposta relação estreita entre doença mental e criminalidade, boa parte continua apontando o rótulo diagnóstico, em termos de entidade nosológica, como elemento-chave para a identificação de periculosidade:

Dentro das psicoses, as paranoides, como as esquizofrenias paranoides, são normalmente mais violentas do que qualquer outra categoria [...] A probabilidade de esquizofrênicos paranoides cometerem crimes graves é maior, graças à sua habilidade de planejamento e concretização. (CORDEIRO, 2003, p.128). 
Junto a comentários em torno da necessidade de relativizar as relações entre doença mental e periculosidade criminal, aparecem afirmações que estabelecem um tipo de identidade perfeita entre ambas. Contudo, percebe-se a reiterada preocupação em diferenciar o diagnóstico nosológico (nome da doença ou transtorno do qual é portador o indivíduo) do diagnóstico descritivo, ou seja, do conjunto de circunstâncias biológicas, psíquicas e sociais sob as quais a doença e a periculosidade se entrelaçam:

O diagnóstico nosológico tem uma importância relativa e, a não ser em casos de indivíduos com personalidade antissocial, de perversos como pedofílicos, de oligofrênicos heréticos e alguns psicóticos, por exemplo, o peso do diagnóstico descritivo tem maior relevância. O diagnóstico psiquiátrico por si só não é indicativo de periculosidade, mas quando esta existe o diagnóstico descritivo pode ser importante na avaliação do tipo de periculosidade [...] (SORDI; KNIJNIK, 2003, p.910).

Observe-se que os diagnósticos mencionados no excerto acima não correspondem, majoritariamente, a doenças. Trata, sim, do que a psiquiatria moderna define como "anomalias" e "transtornos mentais". A noção de "transtorno mental”, e não mais a de loucura, como acontecia nos primórdios e primeiros desenvolvimentos da psiquiatria, é o principal fundamento contemporâneo da medicalização do crime e da periculosidade criminal.

A classe de transtorno que a psiquiatria vincula mais estreitamente à periculosidade criminal é o chamado "transtorno de personalidade". Contudo, alguns autores chegam a questionar a própria permanência desse tipo de transtorno no campo de objetos da psiquiatria:

As divergências ocorrem nos mais diversos planos, e há quem considere essa entidade nosológica como o lado mais contencioso da psiquiatria moderna. Existem ainda aqueles que defendem a extinção dessa categoria diagnóstica, em virtude do julgamento moral e pejorativo que ela desperta, sobrepujando, por vezes, a investigação científica que deve ser a ela dada com o mesmo grau de seriedade que é dispensado a qualquer outro diagnóstico clínico. (ABDALLA-FILHO, 2004a, p.281).

No entanto, a maior parte das divergências parece dissipar-se quando se trata de avaliar a relevância forense dos transtornos de personalidade, como manifesta em outro trecho o autor:

Dentro do contexto forense, os transtornos de personalidade revestem-se de uma importância enorme, uma vez que seus portadores não raramente se envolvem em condutas criminosas e, consequentemente, em processos judiciais, especialmente aqueles que apresentam características do tipo antissocial. (ABDALLA-FILHO, 2004a, p.281). 
Mas não seria qualquer classe de transtorno de personalidade que interessaria especialmente à psiquiatria forense, e sim uma em particular: o "transtorno de personalidade antissocial" (TPAS). Serafim (2003) vai ao encontro da literatura que o enfatiza como uma das principais causas do comportamento criminoso, e traça o seguinte perfil dessa entidade nosológica:

Os aspectos psicológicos desses indivíduos são caracterizados pelo desprezo às obrigaçôes sociais e por uma falta de consideração com os sentimentos dos outros. Exibem um egocentrismo patológico, emoçōes superficiais, falta de autopercepcão, pobre controle da impulsividade (incluindo baixa tolerância para frustração e limiar baixo para descarga de agressão), irresponsabilidade, falta de empatia com outros seres humanos, ausência de remorso, ansiedade e sentimento de culpa em relação ao seu comportamento antissocial [...] e sua anormalidade consiste especificamente em anomalias do temperamento e do caráter, determinando uma conduta anormal configurando uma menos-valia social. (SERAFIM, 2003, p.56)

A principal característica dessa conduta anormal seria a criminalidade violenta. Para sustentar essa associação entre TPAS e tendência ao comportamento criminoso, Serafim (2003) cita uma pesquisa de Rigonatti (1999) realizada em um grupo de condenados por homicídio e estupro no Brasil. Nela, não foram achadas correlaçôes entre doença mental e crime; porém, os resultados apontam para a alta prevalência do transtorno de personalidade antissocial, que estaria presente em $96 \%$ dos homicidas e $84 \%$ dos estupradores.

Do ponto de vista do foco de interesse do presente artigo, interessa observar que, com a independência do estatuto conceitual que possa ter adquirido a noção de TPAS na psiquiatria contemporânea, sua definição, não em termos de doença e sim de transtorno, faz com que se assegure sua permanência como objeto da psiquiatria, tornando-se, assim, elemento estratégico dos processos de medicalização do crime. Se considerarmos válidos os resultados da pesquisa acima, seria possível concluir que, na quase totalidade dos casos, homicídios e estupros deveriam ser definidos como problemas psiquiátricos, em virtude dos transtornos mentais constituírem o motor de sua ocorrência. Tal raciocínio poderia servir de base para potencializar os processos de medicalização da criminalidade nas sociedades contemporâneas.

Nesse sentido, é preciso lembrar que a transposição da barreira que o conceito de doença estabelecia no passado para definir as fronteiras da medicina pode ser em grande parte atribuída à noção de transtorno. Esta amplificou notoriamente as possibilidades de colonização médica do espaço social, ao permitir estender 
seu domínio a praticamente todas as áreas da existência humana (CONRAD, 1992; ILLICH, 1987; MENENDEZ, 1984; FOUCAULT, 1977), passando a incluir todas suas manifestações consideradas anômalas e/ou anormais (CANGUILHEM, 1986).

No campo da psiquiatria, haveria diversas maneiras de categorizar e definir o TPAS. Abdalla-Filho o define como um

[t]ranstorno caracterizado pelos seguintes aspectos: indiferença e insensibilidade diante dos sentimentos alheios; atitude persistente de irresponsabilidade e desprezo por normas, regras e obrigações sociais estabelecidas; incapacidade de manter relacionamentos estabelecidos; baixa tolerância à frustração e baixo limiar para a deflagração da agressividade e violência; incapacidade de experimentar culpa e grande dificuldade de aprender com a experiência ou com a punição que lhe é aplicada; tendência a culpar os outros e a apresentar argumentações e racionalizações plausíveis para explicar um comportamento que leva o portador desse tipo de transtorno a entrar em conflito com a sociedade. (ABDALLA-FILHO, 2004a, p.286)

Alguns autores reservam a expressão "personalidade psicopática" para referirse ao subtipo de TPAS mais propenso ao comportamento criminoso. Assim, para Abdalla-Filho,

[...] o comportamento psicopático é aquele que revela tendência a práticas criminais, com padrão recidivante, sendo encontrado em indivíduos que apresentam uma personalidade transtornada. (ABDALLA-FILHO, 2004, p.172)

Outros autores discordam da expressão "transtorno de personalidade antissocial" e preferem substituí-la por "sociopatia". Como a palavra sugere, nesse caso, a ênfase cai sobre os aspectos sociais do comportamento, em detrimento de suas dimensões intrapsíquicas, para referir-se "[...] globalmente a indivíduos que mostram tendência para atropelar as normas sociais." (FONSECA, 1997, p.510)

A descrição a seguir revela a onipresença de critérios morais na definição da "personalidade delinquente", considerada um subtipo de sociopatia, predominantemente juvenil, pelo psiquiatra português António Fernandes da Fonseca:

Manifesta-se uma tal rebeldia pela indisciplina, pelo erotismo, pela degradação dos costumes, pela toxicodependência e por múltiplos outros $<$ desmandos $>$ de diversa natureza. Entre os delitos mais frequentes praticados por jovens menores costuma apontar-se o roubo (cometido sobretudo por rapazes), a prostituição (praticada pelas raparigas) e a vagabundagem (exercida por jovens dos dois sexos). (FONSECA, 1997, p.511-512) 


\section{$\mathrm{O}$ acting out como estigma da periculosidade criminal}

Esse caráter adjetivante e moralizador da descrição dos transtornos de personalidade de alto potencial criminogênico exibe, de acordo com Delgado (1992), um traço mais ou menos constante da medicina psiquiátrica desde suas origens. Como aponta Foucault (1980, p.97), a teoria da periculosidade tornouse "a grande noção da criminologia e da penalidade" do final do século XIX, e sobrevive atualmente sob novas roupagens e nuances, mas persistindo na função discursiva de fazer com que o indivíduo passe a ser considerado pela sociedade ao nível de suas virtualidades e não de seus atos, não em termos das infrações concretas e sim das potencialidades comportamentais que elas representam.

Por outro lado, na ótica da medicina psiquiátrica, a noção de periculosidade criminal não é utilizada para prever qualquer tipo de crime. Com efeito, a literatura examinada é unânime em estabelecer uma associação estreita entre periculosidade e crimes fundamentalmente caracterizados pelo uso da violência física diretamente praticada contra outros indivíduos, tais como homicídio e estupro.

O principal indício ou sinal de risco de cometer esse tipo de crimes seria o que a psiquiatria define como acting out. No livro dirigido pelo influente psiquiatra francês Henri Ey descreve-se nos seguintes termos sua relevância para compreender a periculosidade criminal:

Essas anomalias do comportamento se manifestam sob o modelo de um impulso frequentemente agressivo, ou de atos mais complexos, às vezes mesmo sob o modelo de um "acting out" que escapa, de certo modo sub-repticiamente, à vontade e à consciência do individuo. (EY et al., 1985, p.1211)

Dessa forma, o indivíduo que não controla seus impulsos é potencialmente perigoso do ponto de vista criminal:

O crime se produz quando um indivíduo, em resposta a impulsos de ordem biológica, psicológica e social, encontra-se numa situação tal que a execução do delito se lhe afigura como saída inevitável ou necessária (Não estamos dizendo que o crime é um acontecimento de caráter fatalista, que o agente do delito é exculpável porque não lhe restava outra alternativa; o crime é, na maioria dos casos, um transtorno da personalidade, não da inteligência: o criminoso -imputável- escolhe mal a sua conduta, não por estar subjugado a forças que não domina, mas porque não tinha perfeita noção de como controlá-las). (ARAUJO; MENEZES, 2003, p.235) 
$\mathrm{O}$ acting out tende a ser visto como um traço relativamente permanente $\mathrm{e}$ revelador de periculosidade, e não como uma condição circunstancial do indivíduo. De certa forma, a periculosidade ainda seria vista na psiquiatria como um estado permanente, como uma essência de certos indivíduos criminosos e mentalmente perturbados. Daí a importância de observar a ausência ou a presença de fatores que permitam governar os impulsos, diminuindo o potencial de periculosidade futura:

Nesse quadro, assumem ainda particular relevância a deficiente integração de normas ético-sociais e ausência de plano de vida sustentado, reagindo predominantemente por impulsos e emoções de acordo com o princípio do prazer imediato. (CORDEIRO, 2003, p.58)

De acordo com esse tipo de perspectiva, os modelos etiológicos predominantemente preconizados pela psiquiatria contemporânea destacam a participação de fatores biológicos e psicoafetivos na constituição de personalidades criminalmente perigosas.

Não foi encontrado nenhum autor ou texto que apontasse apenas um único fator etiológico de periculosidade. Serafim (2003), por exemplo, define três classes de parâmetros: biológicos, psicológicos e sociais. Porém, enfatizam-se os fatores psicológicos, ao remeter à ideia do jurista italiano Luigi Garofalo ${ }^{3}$, segundo a qual o criminoso "é portador de uma anomalia moral e psíquica, uma espécie de lesão ética, a qual seria responsável pela prática de atos delinquentes" (PEIXOTO, 1936 apud SERAFIM, 2003, p.54).

A tradição biologicista, inaugurada no passado a partir dos aportes de Lombroso e Morel, parece ganhar força renovada à luz das tendências mais recentes na interpretação etiológica das anomalias precursoras da periculosidade criminal. Sordi e Knijnic (2003, p.910), por exemplo, referem-se às causas biológicas da periculosidade, definidas como os fatores

[...] relacionados à carga instintiva inata, principalmente agressividade. As alteraçôes fisiológicas e bioquímicas, de um modo geral, mas principalmente relacionadas ao funcionamento cerebral, permanentes ou transitórias, que encontrem expressão na conduta do indivíduo, como ocorre nas patologias relacionadas com alterações da neurotransmissão, tão estudadas atualmente, fazem parte destes fatores.

Seja de forma independente, seja associada aos fatores biológicos, a literatura examinada concede sua máxima atenção aos processos intrapsíquicos de constituição da personalidade transtornada. Entre esses fatores, destaca-se o papel 
do vínculo com as figuras parentais e com a família no surgimento de elementos criminogênicos. De acordo com essa perspectiva, "[...] a violência humana é consequência da perversão dos valores dominantes e do desenvolvimento psicológico provocado por graves perturbações na interação Mãe-Filho-Pai” (CORDEIRO, 2003, p.49). Nesse contexto, a família e, fundamentalmente, a família em condições de pobreza, tende a ser observada como espaço privilegiado para o desenvolvimento do TPAS e da criminalidade que dele decorreria. Entre os indicadores de periculosidade criminal formulados por Maranhão ${ }^{4}$, Araújo e Menezes (2003), destaca-se o caráter criminogênico da "família desagregada":

A família é, sem dúvida, um fator importante na formação da personalidade. O lar só atende às necessidades se cumpre suas funções básicas. Se a mãe, que representa a fonte de afeto, não compreende nem aceita o filho; se o pai, enquanto contato com realidade, é irascível e violento, omisso, ou irresponsável; se a relação com os irmãos é excessivamente belicosa, o filho não desenvolverá adequadamente o sentimento de fraternidade, tão imprescindível nos processos adaptativos, e, não raro, procurará afeto na rua, onde encontrará outros em situação análoga, passando a adotar outros códigos de conduta e, para sobreviver, recorrerá às açōes antissociais, restando a sua readaptação como difícil e trabalhosa. (ARAUJO; MENEZES, 2003, p.240).

Dessa forma, o papel de fatores socioculturais e políticos permaneceria restrito a um caráter mais desencadeante que etiológico propriamente dito. Nessa categoria inscreve-se, preponderantemente, o consumo de substâncias psicoativas:

Pessoas com diagnóstico de transtorno de personalidade do tipo antissocial costumam apresentar consumo precoce inadequado de álcool e outras drogas e problemas com a Justiça. O risco da realização de um crime violento (contra a pessoa) tende a ser aumentado entre indivíduos com o duplo diagnóstico: alcoolismo e transtorno de personalidade antissocial. (POLDRUGO, 1998; BALTIERI; FREITAS, 2003, p.159)

Como observa o antropólogo francês François Laplantine (1991), todos os modelos etiológicos das doenças pressupõem ou convertem-se em fundamento de seus correlatos terapêuticos. Na medida em que se tende a associar etiologicamente a periculosidade criminal com transtornos da personalidade cujas causas pertencem a um passado remoto (intrapsíquico e familiar) e se manifestam num presente percebido como imodificável, a segregação e confinamento dos indivíduos assim diagnosticados acabam sendo as respostas sociais e técnicas em que os universos jurídico-penal e médico, uma vez mais, convergirão.

O caráter incorrigível dos indivíduos tipificados como portadores de TPAS - ideia quase unânime no âmbito da psiquiatria contemporânea -, seria o 
1390 fundamento para propor, como única alternativa, sua segregação do tecido social por meio do encerro, por se tratar de sujeitos "[...] incapazes de aprender com a punição, de modificar seus comportamentos e apresentar respostas fisiológicas a situações de medo" (SERAFIM, 2003, p.56).

\section{Considerações finais}

Embora não se disponha ainda de uma historiografia da psiquiatria forense como especialidade da psiquiatria, a compreensão de suas origens e posteriores desenvolvimentos se vê facilitada pelo fato de a própria psiquiatria ter nascido no Brasil, em grande medida no ramo forense. De forma análoga a processos observados em outros contextos, a psiquiatria brasileira conseguiu precocemente inserir-se como saber experto no poderoso e densamente institucionalizado mundo das leis.

A ampliação dos domínios da medicina ocorreu por meio de estratégias diversificadas, sendo uma delas a que Crawford (1980) caracteriza como a transferência, para o campo de competências da medicina, de objetos anteriormente sob a jurisdição de outras instituições. No que tange à problemática do crime, resulta que - embora de maneira parcial e hierarquicamente subordinada - a psiquiatria forense substituiu a instituição judiciária e seus principais agentes nas funçôes de determinar a (in)imputabilidade penal e a periculosidade criminal de doentes mentais, atributos que até certo momento permaneciam exclusivamente sob o controle do poder judiciário.

A análise das formas de inserção da psiquiatria forense no campo judiciário permite observar a relevância do papel dos seus profissionais como árbitros da criminalidade. De maneira bastante consensual, as pesquisas em torno do tema confirmam a importância que os laudos psiquiátricos assumem para as decisões judiciais em matéria penal, uma vez que a maior parte dos magistrados tenderia a aceitar como válidos os resultados das avaliações realizadas pelos peritos e a emitir suas sentenças de conformidade com eles. (BERCOVICH, 2000). Trata-se de um indicador bastante específico da confiança que o poder judiciário deposita na profissão médica, confirmando assim, uma aliança de larga data entre ambos os universos.

Outro aspecto que merece ser destacado refere-se ao caráter dinâmico dos processos de medicalização do crime. De acordo com a discussão desenvolvida, 
a introdução do conceito de transtorno mental, oficializada por ocasião da formulação da CID-105 , acabou contribuindo de maneira significativa para a reconquista de objetos de conhecimento e intervenção profissionais da psiquiatria forense. Essa nova classificação nosológica permitiu, entre outras coisas, garantir a permanência do diagnóstico de personalidade antissocial como objeto legítimo da psiquiatria, bem como sua utilização, para fins forenses, na avaliação de periculosidade criminal.

Esse dinamismo se estende aos modelos etiológicos em que tais processos se sustentam. Embora a literatura sobre o tema insista no caráter eclético das orientações teóricas dominantes na psiquiatria brasileira, é possível observar certa tendência, principalmente a partir das últimas décadas do século $\mathrm{XX}$, ao desenvolvimento e utilização de modelos interpretativos que preconizam a participação de fatores de natureza predominantemente individual e familiar na etiologia tanto da doença mental como da criminalidade. Observa-se, nesse sentido, uma perda progressiva de consideração do meio (social, cultural, econômico, político) como fator determinante desses fenômenos, e a emergência de um entusiasmo renovado pelos fatores criminogênicos de naturezas bioquímica, genética, orgânica, intrapsíquica e afetivo-vincular. Entre as possíveis consequências socioculturais da utilização desses modelos etiológicos, é preciso destacar sua contribuição à despolitização dos fenômenos da saúde e da criminalidade e, consequentemente, à desresponsabilização das instâncias públicas e coletivas e à responsabilização crescente dos indivíduos e suas famílias na provisão de cuidados e no controle da criminalidade.

Ao mesmo tempo, tais modelos, petrechados numa linguagem cada vez mais sofisticada, e valendo-se de instrumentos diagnósticos aparentemente cada vez mais elaborados, não parecem transportar interpretações sobre as relações entre saúde mental e criminalidade muito diferentes das que inauguraram a psiquiatria forense como área de conhecimento e como profissão. A localização da origem do comportamento criminal na "personalidade" do indivíduo, e a utilização do diagnóstico de personalidade antissocial como estereótipo do criminoso, agora já não mais considerado louco, mas sim "transtornado", conserva (e renova) perturbadoras analogias com a figura lombrosiana do "criminoso nato".

Por outro lado, o caráter profundamente social dos fenômenos em pauta sugere a necessidade de problematizar a organização e a divisão sociotécnica 
1392 dos processos de trabalho orientados à arbitragem da criminalidade vinculada à saúde mental, em função da posição neles ocupada pelo saber médicopsiquiátrico. Nesse sentido, é preciso lembrar que a emissão de laudos periciais caracteriza-se pelo pronunciamento técnico acerca de condições (imputabilidade, periculosidade) que acabam determinando, de maneira dramática, as trajetórias biográficas dos indivíduos, podendo conduzi-los ao confinamento perpétuo em manicômios judiciários.

Nesse sentido, vale a pena lembrar que a luta antimanicomial, o questionamento das condições de vida e a defesa dos direitos da população internada por decisão judicial não têm sido, até o momento, incluídos na agenda da reforma psiquiátrica em curso no Brasil. Nessa direção, o desenvolvimento de pesquisas de caráter sócio-antropológico em torno dessa temática poderia contribuir a estabelecer uma ruptura com esse silenciamento que caracteriza os discursos e as práticas sociais dos mais diversos agentes nesse campo. ${ }^{6}$

\section{Referências}

ABDALLA-FILHO, E. Psiquiatria Forense. Porto Alegre: Artmed, 2004, p. 161-174. . Transtornos da personalidade. In: TABORDA, J.G.; CHALUB, M.; ABDALLAFILHO, E. Psiquiatria Forense. Porto Alegre: Artmed, 2004a. p. 281-295.

ALVARENGA, M.A.S.; FLORES-MENDOZA, C.E.; GONTIJO, D.F. Evolução do DSM quanto ao critério categorial de diagnóstico para o distúrbio da personalidade antissocial. J. bras. Psiquiatr. Rio de Janeiro, v. 58, n. 4, 2009. Disponível em: <http://www.scielo. $\mathrm{br} /$ scielo.php? script $=$ sci_arttext $\&$ pid $=$ S0047-20852009000400007 \&lng=en \&nrm $=$ iso $>$. Accesso em: 25 fev 2011.

ARAUJO, C.T.L.; MENEZES, M.A. Execução penal, exame criminológico e apreciação dos indicadores de potencial criminógeno. In: RIGONATTI, P.S.; SERAFIN, A.P.; BARROS, E.L. de. (Org.). Temas em psiquiatria forense e psicologia jurídica. São Paulo: Vetor, 2003. p. 229-245.

BALTIERI, D.A.; FREITAS, S.P. Álcool e crime. In: RIGONATTI, P.S.; SERAFIN, A.P.; BARROS, E.L de. (Org.). Temas em psiquiatria forense e psicologia jurídica. São Paulo: Vetor, 2003. p. 151-163.

BERCOVICH, I. La medicalización de la sociedad: el caso de la práctica psiquiátrica forense en el Uruguay. Licenciatura en Sociología - Facultad de Ciencias Sociales. Universidad de la República del Uruguay. Montevidéu: 2000. 90 f.

CANGUILHEIM, G. Lo normal y lo patológico. México: Siglo XXI, 1986. 
CAPONI, S. Biopolítica e medicalização dos anormais. Physis, Rio de Janeiro, v. 19, n. 2, p. 529-549, 2009.

CARTRON, L. L'idée de dégénérescence au XIX: exposé dans le cadre du Seminaire de G. Jorland à l'EHESS. Paris: EHESS, 2000.

CONRAD, Peter. Medicalization and Social Control. Annual Review of Sociology, n. 18, p. 209-232, 1992.

CORDEIRO, J.C.D. Manual de Psiquiatria Clinica. Lisboa: Calouste Gulbenkian, 2003.

COSTA, J.F. História da Psiquiatria no Brasil. Rio de Janeiro: Documentário, 1976.

CRAWFORD, R. Healthism and the medicalization of everyday life. International Journal of Health Services, v. 3, n. 10, p. 365-387, 1980.

DARMON, P. Médicos e assassinos na Belle Époque: a medicalização do crime. Rio de Janeiro: Paz e Terra, 1991.

DELGADO, P.G. As razóes da tutela. Psiquiatria, Justiça e Cidadania do Louco no Brasil. Rio de Janeiro: Te Corá, 1992.

DOUGLAS, M. Risk as Forensic Resource. Daedalus, v. 119, n. 4, p. 11-16, 1990.

ELIAS, N. Conocimiento y Poder. Madrid: La Piqueta, 1994.

EY, H.; BERNARD, P.; BRISSET, C. Manual de Psiquiatria. São Paulo: Masson, 1985.

FONSECA, A.F. Psiquiatria e psicopatologia. 2 ed. Lisboa: Calouste Gulbenkian, 1997.

FOUCAULT, M. O poder psiquiátrico: curso dado no Collège de France (1973-1974). São Paulo: Martins Fontes, 2006.

. Os Anormais: curso no Collège de France (1974-1975). São Paulo: Martins Fontes, 2002. . Vigilar y castigar. Nacimiento de la prisión. México: Siglo XXI, 1987.

. La verdad y las formas jurídicas. Barcelona: Gedisa, 1980.

. História da sexualidade I: A vontade de saber. Rio de Janeiro: Graal, 1977.

HARRIS, R. Assassinato e loucura. Medicina, leis e sociedade no fin de siècle. Rio de Janeiro: Rocco, 1993.

ILLICH, I. Némesis médica. La expropiación de la salud. México: Joaquin Moritz-Planeta, 1987.

JACÓ-VILELA, A. et al. Medicina Legal nas Teses da Faculdade de Medicina do Rio de Janeiro (1830-1930): o encontro entre medicina e direito, uma das condições de emergência da psicologia jurídica. Interaçôes, v. X, n 19, p. 9-34, jan-jun 2005.

LAPLANTINE, F. Antropologia da doença. São Paulo: Martins Fontes, 1991.

MENENDEZ, E. Relaciones sociales de cura y control. Notas sobre el desarrollo del modelo médico hegemónico. Revista Paraguaya de Sociología, ano 21, n. 61, p.153-161, 1984.

MITJAVILA, M. El saber médico y la medicalización del espacio social. Montevidéu: Facultad de Ciencias Sociales. Universidad de la República Oriental del Uruguay, 1998. 48 p. 
MORAES, T.; FRIDMAN, S. Medicina Forense, Psiquiatria Forense e Lei. In: TABORDA, G.V.; CHAlUB, M; ABDAllA-FILHO, E. (Org.). Psiquiatria Forense. Porto Alegre: Artmed, 2004. p.21-30.

ORGANIZAÇÃO MUNDIAL DA SAÚDE. Classificação de transtornos mentais e de comportamento da CID-10: descrições clínicas e diretrizes diagnósticas. Porto Alegre: Artmed, 1993.

POLDRUGO, F. Alcohol and criminal behaviour. Alcohol and Alcoholism. v. 1, n. 33, p. 12-15, 1998.

RIGONATTI, S. P. Temas em psiquiatria forense e psicologia jurídica. São Paulo: Vetor, 2003. SERAFIM, A.P. Aspectos etiológicos do comportamento criminoso: parâmetros biológicos, psicológicos e sociais. In: RIGONATTI, P.S.; SERAFIN, A.P.; BARROS, E.L. de. (Org.). Temas em psiquiatria forense e psicologia jurídica. São Paulo: Vetor, 2003. p.49-64.

SORDI, R.E.; KNIJNIK, J. Periculosidade. In: CATALDO NETO, A.; GAUER, G.; FURTADO, N. (Org.). Psiquiatria para estudantes de medicina. Porto Alegre: EdPUC-RS, 2003. p.909-912.

TABORDA, J.G. Exame pericial psiquiátrico. In: TABORDA, M.; CHALUB, E.; ABDALlA-FILHO E. (Org.). Psiquiatria Forense. Porto Alegre: Artmed, 2004. p. 43-67.

VALENCA, A.M.; MORAES, T.M. de. Relação entre homicídio e transtornos mentais. Revista Brasileira de Psiquiatria, v. 28, supl. II, p. S62-8, 2006.

\section{Notas}

${ }^{1}$ Trata-se de uma amostra de tratados e livros de psiquiatria geral e de psiquiatria forense que faz parte do material empírico examinado durante a excução do projeto de pesquisa Discursos Forenses sobre Risco e Periculosidade Criminal: olhares da medicina psiquiátrica na contemporaneidade (2008-2009), atividade realizada com auxílio de uma bolsa de Pós-Doutorado Sênior do CNPq. O tamanho e a composição dessa amostra de manuais e livros foram determinados a partir de um levantamento, realizado em 2009, junto a informantes qualificados, dos materiais bibliográficos predominantemente utilizados como obras de referência pelos psiquiatras forenses no Brasil.

${ }^{2}$ Cláudio Lyra Bastos. Opinião. Coluna da Lista Brasileira de Psiquiatria Psychiatry On-line Brazil, v. 12, n. 10, out 2007. Disponível em http://www.polbr.med.br/ano07/lbp1007.php.

${ }^{3}$ Luigi Garofalo foi um jurista italiano que sustentava a aplicação das penas em função do grau de perversidade do criminoso. Sua obra mestra, La Criminologia, publicada em Turim em 1885, teve grande ressonância e acabou sendo traduzida no mundo inteiro.

${ }^{4}$ Odon Ramos Maranhão (1924-1995) foi professor titular da Faculdade de Direito da Universidade de São Paulo e professor de Criminologia no curso de pós-graduação da mesma faculdade.

${ }^{5} \mathrm{O}$ sistema de Classificação Internacional de Doenças (CID) foi criado pela Organização Mundial da Saúde, no qual diversas doenças mentais foram identificadas, sistematizadas e clinicamente descritas (ALVARENGA; FLORES-MENDOZA; GONTIJO, 2009).

${ }^{6}$ As autoras contribuíram igualmente na elaboração do manuscrito. 
Mental illness and criminal dangerousness in contemporary psychiatry: discursive strategies and etiological models

This paper analyzes some socio-cultural dimensions of the semantic field and ways of structuring forensic psychiatry discourses in relation to the criminal dangerousness and its connections with mental health. From the results of a research based on content analysis of several handbooks and books in forensic psychiatry, it was possible to examine some meanings and forms of enunciation about the concept of criminal dangerousness as well as the main interpretive strategies that organize the etiological models of criminality prevailing in this area.

> Key words: Criminal dangerousness; forensic psychiatry; mental health. 